\title{
Public Trust and Compliance with the Precautionary Measures Against COVID-19 Employed by Authorities in Saudi Arabia
}

This article was published in the following Dove Press journal: Risk Management and Healthcare Policy

\author{
Adel F Almutairi (D' \\ Ala'a BaniMustafa' \\ Yousef M Alessa' \\ Saud B Almutairi ${ }^{2}$ \\ Yahya Almaleh ${ }^{3}$
}

'King Abdullah International Medical Research Center, King Saud Bin Abdulaziz University for Health Sciences, Ministry of National Guard Health Affairs, Riyadh, Saudi Arabia; ${ }^{2}$ Academic Affairs and Training, Ministry of Health, Riyadh, Saudi Arabia; ${ }^{3}$ Private Clinics, Riyadh, Saudi Arabia
Correspondence: Adel F Almutairi King Abdullah International Medical Research Center, King Saud Bin Abdulaziz University of Health Sciences, Ministry of National Guard Health Affairs, Riyadh, Saudi Arabia

Email almutairiadI@ngha.med.sa
Background: The newly emerged and highly infectious coronavirus disease (COVID-19), which first broke out in Wuhan, China, has invaded most countries around the globe. As both the daily positive cases and death toll increase, countries have taken aggressive action to halt its spread. Saudi Arabia recognized the danger early and implemented a series of urgent precautions. Thus, this study aims to evaluate public trust and compliance with the precautionary measures implemented by authorities to combat the COVID-19 outbreak.

Methods: A cross-sectional study was conducted on a sample of the Saudi public using an electronic questionnaire during the COVID-19 outbreak. The data, which were collected using a validated public trust and compliance tool, were analyzed using the chi-square test, $t$ test, and binary logistic regression.

Findings: Of the 1232 participants, there were 655 (53.2\%) males and 577 (46.8\%) females with $34 \pm 10$ years as the mean and standard deviation of their age. Participants demonstrated a high level of trust and agreement $(98.2 \%)$ with the implemented precautionary measures. A positive association between participants' age and their level of agreement with the government actions $(\mathrm{r}=-.082, \mathrm{P}=0.004)$ was observed, with a significant difference between males $(97.1 \pm 6.2)$ and females $(98.0 \pm 4.7)(\mathrm{t}=-2.7, \mathrm{P}=0.006)$. Among the participants, 657 $(53.3 \%)$ were considered to be practicing poor precautionary measures and $575(46.7 \%)$ good precautionary measures. Males $(\mathrm{OR}=1.8$ times, $\mathrm{P}<0.001)$ and those with a school education level $(\mathrm{OR}=1.7$ times, $\mathrm{P}=0.002)$ were more likely to have poor precautionary practices compared to others. Married individuals $(369,49.0 \% ; \mathrm{P}=0.04)$ were more likely to comply with good practices.

Conclusion: A high level of trust was exhibited by the Saudi public in relation to the precautionary measures taken by authorities in Saudi Arabia. Gender, age, marital status, and educational level were found to be significant factors with regard to compliance with precautionary practices.

Keywords: precautionary measures, infectious disease, compliance, public trust

\section{Introduction}

The novel and deadly coronavirus disease (COVID-19), which broke out in December 2019 in Wuhan, China, has been spreading rapidly to more than 162 countries around the globe with more than 6,194,533 people infected (as of June 2, 2020). ${ }^{1,2}$ This type of coronavirus is highly infectious and spreads quickly, leading the World Health Organization WHO to change their declaration of COVID-19 from a global public health emergency to a pandemic on 11 March $2020 .^{3}$ This alarmingly contagious virus is believed to spread person 
to person from direct close contact (within about six feet), through respiratory droplets, when the person who contracted the coronavirus coughs or sneezes. The risk of infection is also exacerbated by the fact that the virus can be transmitted by touching contaminated surfaces or objects, and then touching one's own mouth, nose, or eyes. ${ }^{4}$ Recent studies have shown that the survival of COVID-19 outside the human body varies: for example, it can survive in droplets for up to three hours, up to four hours on copper, up to 24 hours on cardboard, and up to two to three days on plastic and stainless steel. ${ }^{5}$

The clinical presentation of COVID-19 mostly resembles that of Severe Acute Respiratory Syndrome Coronavirus (SERS-CoV) and Middle Eastern Respiratory Syndrome Coronavirus (MERS-CoV): patients usually complain of fever, myalgia or fatigue, and cough, which may or may not be productive. ${ }^{6}$ It is thought that most patients will have a favorable prognosis, except for those who might be at a higher risk of experiencing a severe presentation of the disease, including the increased risk of mortality. For example, the elderly, very young children, pregnant women, immunocompromised patients, and individuals with chronic medical conditions, such as heart disease, diabetes, and lung disease, are at a higher risk of severe illness. ${ }^{6,7}$ These individuals may develop dyspnea and hypoxemia, with the possibility of rapid progression to acute respiratory distress syndrome (ARDS) or organ failure that requires mechanical ventilation. ${ }^{8,9}$

Some countries, such as Saudi Arabia, who quickly identified and understood the seriousness of the outbreak, took the appropriate measures early to deal with the pandemic, resulting in a limited number of cases and slow spread of the virus. Other countries, such as Italy, have seen the virus spread rapidly, leading to thousands of infections and a high death toll. ${ }^{10}$ This virus has placed a significant burden on healthcare systems, with a number of cities in complete lockdown, the banning of travel, and the implementation of curfews to minimize human interactions. As this virus is very contagious - one person could infect approximately 3 to 3.5 others - the WHO recommended people take precautionary measures all the time, even when going out for necessities, including frequent hand washing with alcohol-based products or soap and water, practicing respiratory hygiene, and maintaining social distancing. ${ }^{11}$

Saudi Arabia carefully monitored the virus outbreak in China and other countries, applying strict measures from an early stage, in particular after the WHO declared COVID-19 a pandemic. These measures include school and university closures, temporary suspension of governmental and private work, suspension of international flights, shopping mall shutdowns, and banning any big gatherings, including group prayers in mosques. They also include home isolation for suspected cases and those living with these individuals. The Saudi Ministry of Health launched a number of continuous educational campaigns to increase people's awareness and encourage adherence to the precautionary measures related to infectious diseases, including the importance of the entire population of the country maintaining social distancing. While these intensive precautions might be helpful at reducing transmission of the virus, they must be maintained until a vaccine becomes available; otherwise, cases will again increase once the intervention measures become lenient.

However, these measures might be challenging for the Saudi community as this culture values socialization, including visiting friends, relatives, and family members, as well as providing hospitality. Thus, we aim in this study to examine public trust and compliance with the precautionary measures toward the COVID-19 outbreak implemented by authorities in Saudi Arabia. This study will help improve our understanding of Saudi community behaviors and compliance with precautions during the outbreak, as well as identify the variety of possible reactions toward precautionary measures among the public.

\section{Methods}

\section{Population and Sampling}

This cross-sectional study was conducted on a sample of the general public in Saudi Arabia. The potential participants were selected from the community using social media. In particular, convenience sampling was employed by distributing the questionnaires electronically to the public. Social media is considered a powerful tool for successful recruitment as the study invitation can reach a large number of people in seconds, and it is a major channel for communication and debates in Saudi Arabia. It is also a cost-effective and easy means of recruiting participants who might be hard to reach through traditional recruitment methods. Potential participants can easily read the invitation letter describing the study purpose and potential outcome. Then, they can either fill out the questionnaire or decline the invitation.

Eligible participants were Saudi and non-Saudi men and women who were 18 years or older and residing in Saudi Arabia during the outbreak. The sample size was 
calculated using the sample calculation formula Specifically, based on previous studies conducted in Saudi Arabia, the prevalence of negative attitudes toward infectious disease prevention measures was estimated to be $21.2 \%$, with a margin of error of $3 \%$ and $95 \%$ confidence limits, resulting in a calculated sample size of 712 . Taking into consideration the possible lack of response, we oversampled by $40 \%$, making the final sample size $994 .{ }^{12}$

\section{Data Collection}

The data were collected using a self-administered questionnaire that measures a number of variables, such as public agreement with the precautionary measures enacted by authorities and also their compliance with these measures. The questionnaire is composed of three main sections. The first covers participants' socio-demographic characteristics, including age, gender, nationality, area of residence, and education level. The second section, which contains 13 items, is about participants' compliance with preventive measures. These items are rated on a 5-point Likert scale, ranging from (5) always comply to (1) never comply. The third part is composed of 14 items related to the measures taken by authorities in Saudi Arabia to contain the spread of the virus. Participants indicated their level of agreement on a 5-point Likert scale, ranging from (5) strongly agree to (1) strongly disagree. The content of the questionnaire was adopted from previously published studies, ${ }^{12,13,16,21,22}$ and subjected to a thorough review by public health and social sciences experts, who also monitored the translation into Arabic and back translation into English.

\section{Data Management and Analysis Plan}

SPSS software version 26 was used for the data analysis. Descriptive statistics, such as mean score and standard deviation, as well as frequency and percentages of all independent variables, were also employed. Responses were scored by frequency and percentage then transformed to qualitative data. For compliance, responses of always and often were grouped and considered good practice, whereas responses of never, rarely, and sometimes were considered poor practice. Analytic statistics were applied to examine differences among the sample characteristics and participants' compliance with precautionary measures of infection prevention and control. The chi-square test was used for the qualitative data. Pearson correlation test was used to assess the strength of association between participants' age and their level of agreement with the implemented precautionary measures. To predict the significant factors associated with compliance, logistic regression analysis was applied. A p-value $<0.05$ was considered to be significant.

\section{Ethical Considerations}

Ethical clearance and approval were obtained from the Institutional Review Board at the Ministry of National Guard-Health Affairs (protocol number RC20/141/R). Study participants were informed that their participation was voluntary and their contribution was of great value. No personal identifiers were collected.

\section{Results}

\section{Participants' Socio-Demographic Characteristics}

Over a period of almost two weeks, 1232 members of the public participated in this study by completing the electronic survey. The mean and standard deviation (SD) of participants' age were $34 \pm 10$ years, with 604 participants $(49 \%)$ over 34 years. Genders were nearly equally distributed, with males comprising $53.2 \%$ of the sample. Of the participants, 753 (61.1\%) were married, $213(17.3 \%)$ had a school-level education, and 778 (63.1\%) had a university-level education. The majority of the participants $(853,69.2 \%)$ were employed, and only $393(31.9 \%)$ were healthcare workers. Most individuals (779, 63.2\%) were from the central region of Saudi Arabia. Few participants $(21,1.7 \%)$ indicated that they had previous contact with patients infected with COVID-19. Table 1 presents detailed information on participants' demographics.

\section{Public Trust and Compliance with Precautionary Measures}

Participants rated their extent of agreement with the precautionary measures. The results indicated that $98.2 \%$ were in support of government actions. Table 2 presents the itemized positive and negative responses of participants including percentage mean score (PMS) toward the implemented measures. Pearson correlation test indicated a positive association between participants' age and their level of agreement with the government actions related to the precautionary measures $(\mathrm{r}=-.082, \mathrm{P}=0.004)$. The result of $t$ test indicated a significant difference between males (97.1 \pm 6.2$)$ and females $(98.0 \pm 4.7)$ based on the level of agreement ( $t=-2.7, \mathrm{P}=0.006$ ).

Participants' adherence to infection prevention practices varied, with 657 (53.3\%) considered to be practicing poor 
Table I Socio-Demographic Characteristics of the Study Participants $(\mathrm{N}=1232)$

\begin{tabular}{|c|c|}
\hline Variables & Number (\%) \\
\hline \multicolumn{2}{|l|}{ Age } \\
\hline$>34$ & $604(49)$ \\
\hline$\leq 34$ & $628(5 \mathrm{I})$ \\
\hline$M \pm S D$ & $34 \pm 10$ \\
\hline \multicolumn{2}{|l|}{ Gender } \\
\hline Male & $655(53.2)$ \\
\hline Female & $577(46.8)$ \\
\hline \multicolumn{2}{|l|}{ Educational Level } \\
\hline School & $213(17.3)$ \\
\hline Under-granulate & $778(63.1)$ \\
\hline Post-graduate & $24 \mid(19.6)$ \\
\hline \multicolumn{2}{|l|}{ Marital Status } \\
\hline Married & $753(6 I .1)$ \\
\hline Unmarried & 479 (38.9) \\
\hline \multicolumn{2}{|l|}{ Work Status } \\
\hline Employed & $853(69.2)$ \\
\hline Unemployed & $379(30.8)$ \\
\hline \multicolumn{2}{|l|}{ Healthcare Worker } \\
\hline Yes & $393(31.9)$ \\
\hline No & $839(68.1)$ \\
\hline \multicolumn{2}{|l|}{ Region } \\
\hline Central Region & $779(63.2)$ \\
\hline Other Regions & $453(36.8)$ \\
\hline \multicolumn{2}{|l|}{ Chronic Diseases } \\
\hline Yes & $236(19.2)$ \\
\hline No & $996(80.8)$ \\
\hline \multicolumn{2}{|l|}{ Flu Vaccine } \\
\hline Yes & $255(20.7)$ \\
\hline No & $977(79.3)$ \\
\hline \multicolumn{2}{|l|}{ Contact with Infected COVID-19 } \\
\hline Yes & $21(1.7)$ \\
\hline No & $1211(98.3)$ \\
\hline
\end{tabular}

precautionary measures and 575 (46.7\%) good precautionary measures. The statements that received a high proportion of positive responses were as follows: "obeys night time curfew" with 98.3\%, "avoids public gatherings" with 91.7\%, "maintains social distancing during the COVID-19 outbreak" with $89.3 \%$. The statement "uses a facemask in public" was negatively rated by $54 \%$ of participants, followed by "avoids touching eyes, nose, and mouth with hands" with $37.9 \%$, and "covers nose/mouth when sneezing or coughing with a tissue" with $25.3 \%$. Figure 1 illustrates the participants' responses in more detail.
Bivariate analysis using the chi-square test showed a significant differences between males and females when it comes to good practices related to precautionary measures. Females $(309,53.6 \%)$ were more likely to adhere to good practices than males (266, 40.6\%; $P=0.001$ ). Participants' age was a significant factor, with those older than 34 years $(305,50.5 \%)$ being more likely to adhere to good practices than their younger counterparts $(270,43.0 \% ; P=0.008)$. There was also a significant association between marital status, educational level, and good practice, in which married $(369,49.0 \% ; P=0.04)$ and highly educated people $(128,53.1 \%, P=0.001)$ were more likely to comply with good practices (Table 3 ).

The binary logistic regression analysis also revealed that those who were older than 34 years were less likely ( $\mathrm{OR}=0.74$ times, $\mathrm{p}=0.03$ ) to have poor precautionary practices compared to younger people. Males $(\mathrm{OR}=1.8$ times, $\mathrm{p}<0.001)$ and those with school education level $(\mathrm{OR}=1.7$ times, $\mathrm{p}=0.002$ ) were more likely to have poor precautionary practices compared to others (Table 4 ).

\section{Discussion}

Public trust refers to community members' confidence that the precautionary measures against the infectious disease, the COVID-19 outbreak in this case, implemented by authorities are in people's best interests. Mistrust in the healthcare system could stop people from complying with precautionary measures during outbreaks, as highlighted by a recent study conducted in the Republic of Congo during the 2018 Ebola outbreak. ${ }^{13}$ In their study, the authors found that a higher level of trust was positively correlated with help seeking related to medical care and accepting vaccinations. ${ }^{13}$ The current study findings were encouraging, as the Saudi community expressed a high degree $(98.2 \%)$ of agreement and support with the precautionary measures taken by authorities in response to the COVID-19 outbreak. Given that some of the precautionary measures were unprecedented in the history of Saudi Arabia and related to fundamental elements of Saudi culture, such as the suspension of congressional prayers and Umrah (pilgrimage to Mecca) and also the ban on public gatherings, the public exhibited a high level of trust and ability to compromise.

This trust and confidence with the actions taken has led to the effective containment of the outbreak as indicated by the low rate of daily positive cases being announced compared to those in other countries. As of June 2, 2020, the death rate in Saudi Arabia due to COVID-19 was 
Table 2 Participants' Agreement with the Precautionary Measures Against the Newly Emerged Coronavirus (COVID-19)

\begin{tabular}{|c|c|c|c|}
\hline $\begin{array}{l}\text { To What Extent Do You Agree with the Following } \\
\text { Precautionary Measures }\end{array}$ & $\begin{array}{l}\text { Strongly Disagree/ } \\
\text { Disagree, } \mathbf{N}(\%)\end{array}$ & $\begin{array}{l}\text { Strongly Agreel } \\
\text { Agree, } \mathbf{N}(\%)\end{array}$ & $\begin{array}{l}\text { PMS \% } \pm \text { SD } \\
97.6 \pm 5.6\end{array}$ \\
\hline Restrictions on travel & $28(2.3)$ & 1204 (97.7) & $98.3 \pm 8.6$ \\
\hline Night time curfew & $30(2.4)$ & $1202(97.6)$ & $97.7 \pm 9.2$ \\
\hline School and University closures & $23(1.9)$ & $1209(98.1)$ & $98.3 \pm 8.1$ \\
\hline Workplace closures & $55(4.5)$ & II $77(95.5)$ & $96.1 \pm 11.2$ \\
\hline Suspension of Umrah & $57(4.6)$ & $1175(95.4)$ & $96.6 \pm 12.2$ \\
\hline Suspension of congregational prayer & $|2|(9.8)$ & IIII (90.2) & $92.8 \pm 17.5$ \\
\hline Shopping malls closures & $52(4.2)$ & $1180(95.8)$ & $96.9 \pm 10.7$ \\
\hline Barber shops and beauty salons closures & $23(1.9)$ & $1209(98.1)$ & $98.4 \pm 8.0$ \\
\hline Suspension of GYMs and sport activities & $26(2.1)$ & $1206(97.9)$ & $97.9 \pm 9.3$ \\
\hline Public transportation closures & $35(2.8)$ & II $97(97.2)$ & $97.6 \pm 9.7$ \\
\hline Ban on public gatherings & $16(1.3)$ & $1216(98.7)$ & $98.8 \pm 6.6$ \\
\hline Isolation of COVID-19 cases in special hospitals & $7(0.6)$ & $1225(99.4)$ & $99.4 \pm 4.5$ \\
\hline Restrictions on travel from/to areas of disease & $19(1.5)$ & $1213(98.5)$ & $98.7 \pm 7.1$ \\
\hline $\begin{array}{l}\text { Precautionary measures taken by the Ministry of Health to } \\
\text { contain virus spread }\end{array}$ & $23(1.9)$ & $1209(98.1)$ & $98.2 \pm 8.1$ \\
\hline
\end{tabular}

$0.60 \%$, which is considered below the global average of $6.08 \% .^{2}$ One of the significant indirect causes of death is overwhelmed healthcare systems, in which there are not enough intensive care unit (ICU) beds or ventilators. A possible explanation of the Saudi public's trust is that they quickly adopted and implemented the suggested precautionary measures. Interestingly, the current study findings showed that there is a positive association between age and level of trust as people tend to be more mature and wiser with age. Although both genders exhibited a high degree of trust, females were more likely to agree with the strict measures compared to males. This could be due to the fact that males, in Saudi culture, tend to spend more time outdoors and are required to perform congressional prayers in mosques. ${ }^{14}$

Although the study participants exhibited variations with regards to the degree of compliance with infection prevention practices, females $(309,53.6 \%)$ tended to be more likely to comply with good precautionary practices than males $(266,40.6 \%)$. This finding suggests that females were more cautious, taking the risk of infection more seriously than males, an observation supported by previous studies. ${ }^{15,17}$ The participant's age was also a significant factor related to compliance with precautionary measures: those who were younger than 34 years were more likely to practice poor precautionary measures than their older counterparts. This result was also observed in a large number of other studies undertaken in different countries. ${ }^{18,20}$ For example, a study conducted by Balkhy and her colleagues regarding the Saudi public's attitudes and practices related to influenza A (H1N1) found that a high level of precaution taking was significantly associated with age. $^{18}$

Many studies in the literature concerning compliance with infection prevention and control measures related to different pathogens causing respiratory infections indicated educational level and marital status were significantly associated with compliance. ${ }^{18,20}$ This finding also was demonstrated in our study, where the higher the education level, the greater the compliance with precautions. Although married people were more likely to adhere to precautions compared to unmarried individuals, it must be noted that married people were also generally older and age was a significant factor related to compliance.

Although the strength of our study is the fact that it was conducted during the COVID-19 outbreak and the sample was generally representative of Saudis in all regions, a larger sample size with participants from every part of the country could confirm our findings and support their generalizability. Participation was also limited to social media and smartphone users, the mean age is $34 \pm 10$ years, with leaving the views of other community members unexplored. In addition, this study was limited by the short data collection time (two weeks), but it was conducted during the peak of disease spread. Despite these limitations, the study findings can be 


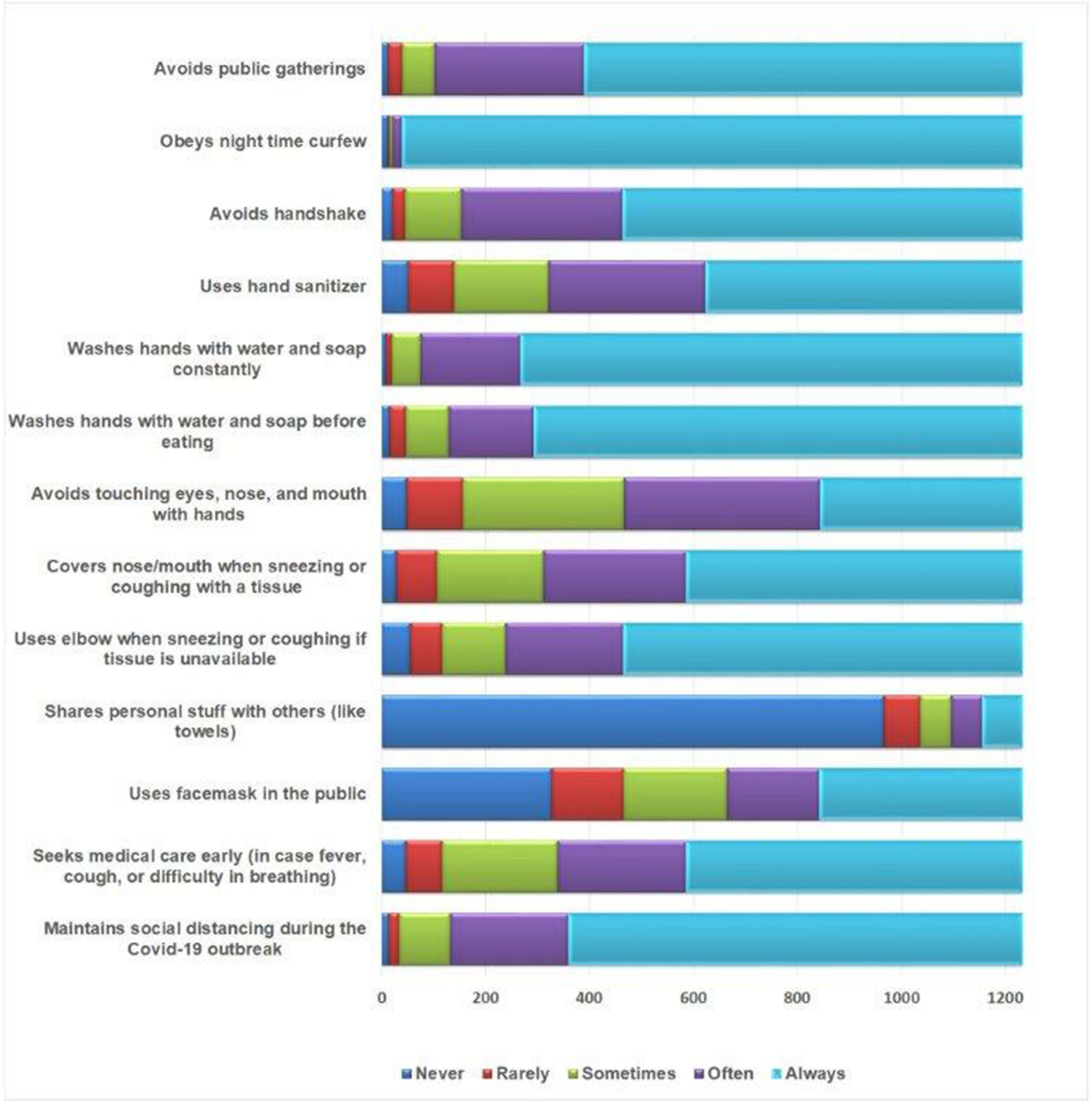

Figure I Participants' practices of the precautionary measures against the newly emerged Coronavirus (COVID-19) (N=1232).

generalizable to other communities with similar sociocultural characteristics.

\section{Conclusion}

This study revealed a high degree of public trust in the Saudi healthcare system and authorities to contain the spread of the COVID-19 outbreak. The precautionary measures to contain this disease were unprecedented, and although many of these measures were inconsistent with Saudi culture, the Saudi community showed a high degree of agreement and compliance with the actions taken. Public trust in these precautionary measures has resulted in the slow growth of COVID-19 and only a $1.2 \%$ death rate in this country. While most of the participants showed a high level of compliance with the precautions, this study revealed important variables, such as age, gender, marital status, and education level, related to different degrees of compliance. Our study found that 
Table 3 Relationship Between Participants' Characteristics and Their Poor and Good Precautionary Practices

\begin{tabular}{|c|c|c|}
\hline & $\begin{array}{l}\text { Poor Practice } \\
(n=657,53.3 \%) \\
N(\%)\end{array}$ & $\begin{array}{l}\text { Good Practice } \\
(n=575,46.7 \%) \\
N(\%)\end{array}$ \\
\hline \multicolumn{3}{|l|}{ Gender } \\
\hline Male & 389 (59.4) & $266(40.6)$ \\
\hline \multirow[t]{2}{*}{ Female } & $268(46.4)$ & $309(53.6)$ \\
\hline & \multicolumn{2}{|c|}{$X^{2}=20.645, P<0.00 I^{*}$} \\
\hline \multicolumn{3}{|l|}{ Age } \\
\hline$>34$ & $299(49.5)$ & $305(50.5)$ \\
\hline \multirow[t]{2}{*}{$\leq 34$} & $358(57.0)$ & $270(43.0)$ \\
\hline & \multicolumn{2}{|c|}{$X^{2}=6.964, P=0.008^{*}$} \\
\hline \multicolumn{3}{|l|}{ Marital Status } \\
\hline Married & $384(51.0)$ & $369(49.0)$ \\
\hline \multirow[t]{2}{*}{ Unmarried } & $273(57.0)$ & $206(43.0)$ \\
\hline & \multicolumn{2}{|c|}{$X^{2}=4.231, P=0.040 *$} \\
\hline \multicolumn{3}{|l|}{ Educational Level } \\
\hline School & $136(63.8)$ & 77 (36.2) \\
\hline Undergraduate & $408(52.4)$ & $370(47.6)$ \\
\hline \multirow[t]{2}{*}{ Postgraduate } & $113(46.9)$ & $128(53.1)$ \\
\hline & \multicolumn{2}{|c|}{$X^{2}=13.735, P=0.00 I^{*}$} \\
\hline \multicolumn{3}{|l|}{ Work Status } \\
\hline Employed & $453(53.1)$ & $400(46.9)$ \\
\hline \multirow[t]{2}{*}{ Unemployed } & $204(53.8)$ & $175(46.2)$ \\
\hline & \multicolumn{2}{|c|}{$X^{2}=0.055, P=0.815$} \\
\hline \multicolumn{3}{|l|}{ Healthcare } \\
\hline \multicolumn{3}{|l|}{ Worker } \\
\hline Yes & $199(50.6)$ & $194(49.4)$ \\
\hline \multirow[t]{2}{*}{ No } & $458(54.6)$ & $38 I(45.4)$ \\
\hline & \multicolumn{2}{|c|}{$X^{2}=1.680, P=0.195$} \\
\hline \multicolumn{3}{|l|}{ Region } \\
\hline Central Region & $40 \mathrm{I}(5 \mathrm{I} .5)$ & $378(48.5)$ \\
\hline \multirow[t]{2}{*}{ Other Regions } & $256(56.5)$ & $197(43.5)$ \\
\hline & \multicolumn{2}{|c|}{$X^{2}=2.919, P=0.088$} \\
\hline \multicolumn{3}{|l|}{ Chronic Diseases } \\
\hline Yes & $117(49.6)$ & $119(50.4)$ \\
\hline \multirow[t]{2}{*}{ No } & $540(54.2)$ & $456(45.8)$ \\
\hline & \multicolumn{2}{|c|}{$X^{2}=1.651, P=0.199$} \\
\hline \multicolumn{3}{|l|}{ Flu Vaccine } \\
\hline Yes & $119(46.7)$ & $136(53.3)$ \\
\hline \multirow[t]{2}{*}{ No } & $538(55.1)$ & 439 (44.9) \\
\hline & \multicolumn{2}{|c|}{$X^{2}=5.733, P=0.017$} \\
\hline
\end{tabular}

Note: *Statistically significant at $<0.05$.

Abbreviations: $\mathrm{n}$, number; $\chi^{2}$, Pearson's chi-square; $\mathrm{SD}$, standard deviation; $\mathrm{P}, \mathrm{P}$-value.
Table 4 Factors Associated with Participants' Poor Practice of Precautionary Measures

\begin{tabular}{|c|l|l|l|l|}
\hline & $\boldsymbol{\beta}$ & S.E. & P-value & OR (95\% CI) \\
\hline $\begin{array}{c}\text { Age } \\
(>34 \text { vs } \leq 34)\end{array}$ & -.300 & 0.138 & $0.030 *$ & $0.741(0.56-0.97)$ \\
\hline $\begin{array}{c}\text { Gender } \\
\text { (Males vs Females) }\end{array}$ & 0.578 & 0.122 & $0.000 *$ & $1.782(1.4-2.7)$ \\
\hline $\begin{array}{c}\text { Marital Status } \\
\text { (Married vs } \\
\text { Unmarried) }\end{array}$ & -.184 & 0.144 & 0.201 & $0.832(0.63-1.1)$ \\
\hline $\begin{array}{c}\text { Work Status } \\
\text { (Employed vs } \\
\text { Unemployed) }\end{array}$ & 0.067 & 0.142 & 0.637 & $1.069(0.81-1.4)$ \\
\hline $\begin{array}{c}\text { Education } \\
\text { (School vs University) }\end{array}$ & 0.513 & 0.166 & $0.002 *$ & $1.671(1.21-2.31)$ \\
\hline
\end{tabular}

Note: *Significance of $p<0.05$.

Abbreviations: $\beta$, coefficient of determination; S.E., standard error; OR, odds ratio; $\mathrm{Cl}$, confidence interval.

female, older, and more educated individuals respected the precautionary measures more than other groups. Therefore, education programmes/campaigns related to compliance should target these other groups to increase awareness of the importance of compliance to halt the spread of the disease.

\section{Acknowledgment}

The authors would like to thank the study's participants without whom the project would not have been possible.

\section{Disclosure}

The authors report no conflicts of interest in this work.

\section{References}

1. Gao J, Tian Z, Yang X. Breakthrough: chloroquine phosphate has shown apparent efficacy in treatment of COVID-19 associated pneumonia in clinical studies. Biosci Trends. 2020;14(1):72-73. doi:10. 5582/bst.2020.01047

2. World Health Organization. Coronavirus Disease 2019 (COVID-19): Situation Report, 134; 2020.

3. Peeri NC, Shrestha N, Rahman MS, et al. The SARS, MERS and novel coronavirus (COVID-19) epidemics, the newest and biggest global health threats: what lessons have we learned? Int $J$ Epidemiol. 2020. doi:10.1093/ije/dyaa033

4. Kang M, Wu J, Ma W, et al. Evidence and characteristics of human-tohuman transmission of 2019-nCoV. medRxiv. 2020.

5. van Doremalen N, Bushmaker T, Morris DH, et al. Aerosol and surface stability of SARS-CoV-2 as compared with SARS-CoV-1. $N$ Engl J Med. 2020;382(16):1564-1567. doi:10.1056/NEJMc2004 973 
6. Lai -C-C, Shih T-P, Ko W-C, Tang H-J, Hsueh P-R. Severe acute respiratory syndrome coronavirus 2 (SARS-CoV-2) and corona virus disease-2019 (COVID-19): the epidemic and the challenges. Int J Antimicrob Agents. 2020;55:105924. doi:10.1016/j.ijantimicag.20 20.105924

7. COVID C. Severe Outcomes Among Patients with Coronavirus Disease 2019 (COVID-19)_United States, February 12-March 16, $2020 ; 2020$.

8. Organization WH. Clinical Management of Severe Acute Respiratory Infection (SARI) When COVID-19 Disease Is Suspected: Interim Guidance, 13 March 2020. World Health Organization; 2020.

9. Goh KJ, Kalimuddin S, Chan KS. Rapid progression to acute respiratory distress syndrome: review of current understanding of critical illness from COVID-19 infection. Ann Acad Med Singapore. 2020;49(1):1.

10. Paterlini M. On the front lines of coronavirus: the Italian response to COVID-19. BMJ. 2020;368. doi:10.1136/bmj.16968

11. Liu Y, Gayle AA, Wilder-Smith A, Rocklöv J. The reproductive number of COVID-19 is higher compared to SARS coronavirus. J Travel Med. 2020.

12. Alhazmi AM, Alshammari SA, Alenazi HA, et al. Community's compliance with measures for the prevention of respiratory infections in Riyadh, Saudi Arabia. J Family Community Med. 2019;26(3):173.

13. Vinck P, Pham PN, Bindu KK, Bedford J, Nilles EJ. Institutional trust and misinformation in the response to the 2018-19 Ebola outbreak in North Kivu, DR Congo: a population-based survey. Lancet Infect Dis. 2019;19(5):529-536. doi:10.1016/S1473-3099(19)30063-5

14. Alsubaie AS, Omer EO. Physical activity behavior predictors, reasons and barriers among male adolescents in Riyadh, Saudi Arabia: evidence for obesogenic environment. Int J Health Sci. 2015;9 (4):400. doi:10.12816/0031229
15. Ward D. Gender differences in compliance with infection control precautions. Br J Infect Control. 2004;5(1):17-19. doi:10.1177/ 14690446040050010401

16. Anand T. Development and Testing of a Scale to Measure Trust on Public Health Care System. SCTIMST; 2014.

17. Gershon RR, Vlahov D, Felknor SA, et al. Compliance with universal precautions among health care workers at three regional hospitals. Am J Infect Control. 1995;23(4):225-236. doi:10.1016/01966553(95)90067-5

18. Balkhy HH, Abolfotouh MA, Al-Hathlool RH, Al-Jumah MA. Awareness, attitudes, and practices related to the swine influenza pandemic among the Saudi public. BMC Infect Dis. 2010;10(1):42. doi:10.1186/1471-2334-10-42

19. Paudel M, Acharya B, Adhikari M. Social determinants that lead to poor knowledge about, and inappropriate precautionary practices towards, avian influenza among butchers in Kathmandu, Nepal. Infect Dis Poverty. 2013;2(1):10. doi:10.1186/2049-9957-2-10

20. Taylor M, Raphael B, Barr M, Agho K, Stevens G, Jorm L. Public health measures during an anticipated influenza pandemic: factors influencing willingness to comply. Risk Manag Healthc Policy. 2009;2:9. doi:10.2147/RMHP.S4810

21. Blair RA, Morse BS, Tsai LL. Public health and public trust: survey evidence from the Ebola Virus Disease epidemic in Liberia. Soc Sci Med. 2017;172:89-97. doi:10.1016/j.socscimed.2016.11.016

22. Abolfotouh MA, AlQarni AA, Al-Ghamdi SM, Salam M, Al-Assiri $\mathrm{MH}$, Balkhy HH. An assessment of the level of concern among hospital-based health-care workers regarding MERS outbreaks in Saudi Arabia. BMC Infect Dis. 2017;17(1):4. doi:10.1186/s12879016-2096-8
Risk Management and Healthcare Policy

\section{Publish your work in this journal}

Risk Management and Healthcare Policy is an international, peerreviewed, open access journal focusing on all aspects of public health, policy, and preventative measures to promote good health and improve morbidity and mortality in the population. The journal welcomes submitted papers covering original research, basic science, clinical \& epidemiological studies, reviews and evaluations,

\section{Dovepress}

guidelines, expert opinion and commentary, case reports and extended reports. The manuscript management system is completely online and includes a very quick and fair peer-review system, which is all easy to use. Visit http://www.dovepress.com/testimonials.php to read real quotes from published authors. 